\title{
TUBERCULOSIS PATIENTS SUBMITTED TO SUPERVISED TREATMENT. RIBEIRÃO PRETO - SÃO PAULO - BRAZIL. 1998 AND $1999^{1}$
}

\author{
Paula Hino ${ }^{2}$ \\ Claudia Benedita dos Santos ${ }^{3}$ \\ Tereza Cristina Scatena Villa \\ Jordana Nogueira Muniz \\ Aline Aparecida Monroe ${ }^{6}$
}

Hino P, Santos CB, Villa TCS, Muniz JN, Monroe AA. Tuberculosis patients submitted to supervised treatment. Ribeirão Preto - São Paulo - Brazil. 1998 and 1999. Rev Latino-am Enfermagem 2005 janeiro-fevereiro; 13(1):27-31.

This study presents a survey conducted among 132 Tuberculosis patients submitted to Supervised Treatment between 01/1998 and 12/ 1999, with a view to describing epidemiological aspects, according to the gender, (final) treatment result and HIV immunology result variables. The number of patients covered by Supervised Treatment rose from $19 \%$ to $30 \%$. For each of these years, $64 \%$ and $71 \%$ of the patients were male, while $89 \%$ and $77 \%$ evolved towards cure. The rate of abandonment increased from $7 \%$ to $10 \%$, while $4 \%$ and $10 \%$ of the patients died of Tuberculosis. The Tb/HIV co-infection represented $22 \%$ and $42 \%$ of the cases. The obtained results disclosed a tendency towards the gradual amplification of Supervised Treatment and its implementation implied important changes in the epidemiological indices of Tuberculosis.

DESCRIPTORS: tuberculosis; acquired immunodeficiency syndrome; treatment outcome

\section{ENFERMOS DE TUBERCULOSIS SOMETIDOS AL TRATAMIENTO SUPERVISADO (TS). RIBEIRÃO PRETO - SÃO PAULO - BRASIL. 1998 Y 1999}

El estudio presenta un inventario realizado con 132 enfermos de Tuberculosis, sometidos al Tratamiento Supervisado desde 01/1998 hasta 12/1999, con el objetivo de describir aspectos epidemiológicos de acuerdo con las variables sexo, resultado de tratamiento y resultado de serología para HIV. La cobertura aumentó de 19\% a 30\%, con 64\% y 71\% del sexo masculino; 89\% y 77\% evolucionaron a la recuperación. Es posible explicar la disminución por la inclusión de pacientes de AIDS que son tratados en una de las Unidades existentes. Ocurrió un aumento de la tasa de abandono de $7 \%$ a 10\% y $4 \%$ y $10 \%$ de los enfermos fallecieron por Tuberculosis. La coinfección Tb/HIV representó 22\% y $42 \%$ de los casos. Los resultados manifiestan una tendencia en ampliar el Tratamiento Supervisado gradualmente pues su implantación puede implicar importantes alteraciones en los indicadores epidemiológicos de la Tuberculosis.

DESCRIPTORES: tuberculosis; síndrome de inmunodeficiencia adquirida; resultado del tratamiento

\section{DOENTES DE TUBERCULOSE SUBMETIDOS AO TRATAMENTO SUPERVISIONADO. RIBEIRÃO PRETO - SÃO PAULO - BRASIL. 1998 E 1999}

O trabalho apresenta um levantamento realizado com 132 doentes de Tuberculose, submetidos ao Tratamento Supervisionado no período de 01/1998 a 12/1999, com objetivo de descrever aspectos epidemiológicos segundo as variáveis sexo, resultado de tratamento e resultado de sorologia para HIV. A cobertura aumentou de 19\% para 30\%, sendo 64\% e 71\% do sexo masculino; $89 \%$ e $77 \%$ evoluíram para a cura. Este decréscimo pode ser explicado pela inclusão dos doentes de AIDS tratados em uma das Unidades existentes. Houve um aumento da taxa de abandono de $7 \%$ para $10 \%$ e $4 \%$ e $10 \%$ dos doentes foram a óbito por Tuberculose. A co-infecção Tb/HIV representou 22\% e $42 \%$ dos casos. Os resultados evidenciaram uma tendência em ampliar o Tratamento Supervisionado gradativamente, pois sua implantação pôde implicar em importantes alterações nos indicadores epidemiológicos da Tuberculose.

\section{DESCRITORES: tuberculose; síndrome de imunodeficiência adquirida; resultado de tratamento}

\footnotetext{
${ }^{1}$ The authors are grateful to the Municipal Health Secretary of Ribeirão Preto for authorizing data collection and to the São Paulo State Research Support Foundation - FAPESP, for the research grant; ${ }^{2}$ Nurse, Master Student; ${ }^{3}$ Statistics, PhD, e-mail: cbsantos@eerp.usp.br; ${ }^{4}$ Nurse, Associate Professor. University of São Paulo at Ribeirão Preto College of Nursing - WHO Collaborating Center for Nursing Research Development; ${ }^{5}$ Nurse, Doctoral Student, Coordinator of the Tuberculosis Control Program of Ribeirão Preto; ${ }^{6}$ Nurse, Doctoral Student, University of São Paulo at Ribeirão Preto College of Nursing - WHO Collaborating Center for Nursing Research Development
} 


\section{INTRODUCTION}

In spite of the efforts undertaken on a global scale, Tuberculosis (Tb) is still an important threat to public health. The advances in the knowledge and technology available to control it have not been enough to cause a significant impact in its mortality, mainly in developing countries ${ }^{(1)}$.

It is estimated that, nowadays, 3 million deaths and 8 million new Tb cases occur every year, while one third of the population may be infected. Various factors have been pointed out globally as being capable of creating favorable conditions for the increase in Tb cases, such as: poor public health services, deficient socioeconomic situation, growth of marginal population, drugs abuse and HIV-AIDS epidemic. In Brazil, 130,000 new Tb cases occur every year, while more than 10,000 lives are probably lost as a result of the disease. The country occupies the $13^{\text {th }}$ place in the list of 22 countries responsible for approximately $80 \%$ of Tb cases all over the world. In 1999, the occurrence of the disease in the country corresponded to $48 / 100,000$ inhabitants. In 1998, the mortality rate was $3.5 / 100,000 ; 67 \%$ of the cases were detected, while the percentage of cured patients was $72 \%$. The treatment abandonment percentage fluctuated around $14 \%$ in Brazil, reaching 30 to $40 \%$ in some state capitals, which probably leads to high medication resistance rates. Anti-Tb medication resistance profile is evaluated in less than $5 \%$ of the diagnosed cases ${ }^{(2)}$.

The factors that impede the effective control of Tb throughout the world are related to prevention, diagnosis and treatment problems, as well as the poor quality of health services. Another factor is the scarcity of basic biological knowledge about the bacillus and the parasitehost relation, which could provide new intervention targets for Tb control. In view of this scenario, the World Health Organization (WHO) declared Tb to be a global emergency and recommended global strategies for effective Tb control in the countries ${ }^{(3)}$. One of these is Directly Observed Treatment (DOT), whose main aim is the reduction of Tb mortality, morbidity and transmission. Supervised Treatment (ST) comes up as an essential part of the DOT strategy and consists of the direct administration of the medicine by a second person, who delivers, observes and records the ingestion of each medication dose. The main aim of this intervention is the patients' cure and the consequent reduction in the rates of abandonment and disease transmission within the community. The importance of this treatment is valued in the sense of breaking the epidemiological chain of the disease, which decreases transmission risks within the family and the community.

Besides changing the epidemiological profile of Tb, ST presents other advantages, such as: available and low-cost treatment, since hospitalization is not needed and defense against the development of multi-resistant M. tuberculosis lineage, which results from repeated therapies, incomplete and unsuccessful treatments ${ }^{(4)}$. ST is considered to be the most significant advance in $\mathrm{Tb}$ treatment over the last 25 years and is seen as standard treatment in the USA nowadays. In 1950, ST was instituted in Hong Kong and was reported for the first time by FOX (India), indicating quite satisfactory results ${ }^{(5)}$. Other countries also implemented the DOT strategy successfully, such as: Tanzania, China, Peru, Bangladesh, Nepal; they are already displaying improved epidemiological indices, which result from decreased abandonment and increased cure rates. The goals proposed by the ST, that is, the implemented measures, have positively interfered in the program performance indices. In all cases, increased cure rates and decreased abandonment rates were observed. Epidemiological models indicate that, in 10 to 15 years, the dissemination and careful development of the ST, especially in the 15 countries most affected by endemic $\mathrm{Tb}$, could halve the disease occurrence rate. It is estimated that 10 million $\mathrm{Tb}$ deaths could be avoided in this period. Nevertheless, globally speaking, the strategy still needs to be used on a larger scale. When the system was defined in 1993, a mere $2 \%$ of active Tb cases was treated by this method. Nowadays, estimates indicate almost $12 \%$, which reflects an expansion that is marked, but not nearly enough. Preliminary WHO studies suggest that the number of Tb cases could be reduced along with the expansion of ST. The adoption of this measure will demand both additional resources and a supportive governmental policy, particularly in the 15 countries responsible for about $75 \%$ of active $\mathrm{Tb}$ cases, including Brazil.

The Municipal Health Secretariat develops all of the actions of the Tuberculosis Control Program (TCP), such as: self-administered treatment (AT), ST, BCG vaccination, PPD test, doctor's appointments, Nursing care, preliminary and post-treatment appointments and home visits. The proposal to implement ST in Ribeirão Preto was stimulated by the São Paulo Epidemiological Control Center (TCP reference point in the state), which presented the strategy as a possibility for improving cure rates and diminishing the amount of patients who abandoned the treatment. The municipality's epidemiological situation was also considered. Its indices (population higher than 50 thousand inhabitants; average occurrence coefficient in the last five years corresponding to $56 / 100,000$ inhabitants; average abandonment rate in the last five years was $16 \%$ and average cure rate was $50 \%$; in the last two years, the average Tb/HIV co-infection rate was $29 \%$ ) demonstrated the need to implement changes in the program actions. Thus, in 1995, the municipality was chosen as one of the priorities for Tb combat.

The São Paulo State Tb Control Division suggests ST to be offered to all patients under treatment. Nevertheless, it is observed that the teams chose to give priority to risk components within the inclusion process, due to human and material resource restrictions (transport, basic food packages, and bus tickets). It should be highlighted that, although the criteria for ST inclusion were predetermined by the professional, this does not mean that they rule on all cases. The inclusion 
requires an individual and specific evaluation of each case, and sometimes other analyses and common sense. The Tb patients chosen for ST are those groups with the highest treatment abandoning risk, such as: alcoholics; drugs users; beggars or homeless persons; people living in closed communities, such as shelters and prisons; people with comprehension difficulties due to cultural deficiencies or old age; minors whose tutors do not assume the treatment and people in a precarious social situation.

ST implementation demanded the reallocation of staff and redefinition of functions, as well as the introduction of new professionals in those services where the number of professionals was insufficient for developing the strategy.

In a next step, the TCP was decentralized, accompanying the district division process. In 1995, the function of TCP coordinator was created at the Epidemiological Control Division of the Municipal Health Secretariat. Thus, the municipality started to manage the TCP, attending to the competencies established by the National Health Pneumology Coordination. As a result of the administrative and operational decentralization of the National Tb Control Program, 5 reference units for $\mathrm{Tb}$ treatment were constituted in the health districts.

\section{METHODOLOGY}

Research field

Ribeirão Preto is located in the interior of São Paulo, at about 319 kilometers from the state capital. According to data from the Brazilian Institute of Geography and Statistics (IBGE), population was estimated at 467,906 (52\% female) and 473,274 (52\%) for 1998 and 1999, respectively. Data from the 2000 census determined a population of 504,923 inhabitants (52\%). For the period from 2001 to 2003, the estimated population corresponds to 514,160 (52\%); 520,501 (52\%) and 527,734 (52\%), respectively. It hosts one of the country's main financial centers and presents a strong service and commerce sector, concentrating $65 \%$ of the municipality's economically active population.

Study type and population

This is a retrospective and exploratory cross-sectional study. The study population consisted of 132 cases of Tb patients registered in the TCP.

Data collection

Data were collected from the Epi-Tb database of the TCP, which is part of the Epidemiological Control Center of the Municipal
Health Secretariat. The data were adapted from the Epi-Info computer program and were standardized for São Paulo State with a view to storing Tb patient information, which allows for a monthly follow-up, with information sent by the Health Districts after filling out the compulsory notification forms. Although the Tb notification and control form does not contain further details, it revealed to be a simple and objective instrument for data collection, in which could find the necessary information for evaluating some epidemiological aspects (in these cases, patient records had to be consulted).

Information flow

Every health service that identifies a Tb patient is obliged to fill out the form, even if the case is not new and was already notified by another health service. The original of the notification form must be sent within a maximum of 15 days, following the established data transmission flow, so that the data can be put into the Epi-Tb program in the municipality. Before data input, the consistency of the form is checked. A patient must have one form in the Epi-Tb for each treatment. Multiple notification for one single patient is detected by comparing data such as the patient's name, the name of the patient's mother and the birth date. Hence, the precise registration of these data is important to be able to compare them with the notifications realized by another health service.

Information about treatment result is requested by means of the Epi-Tb Updating Report, which is sent to the health units every month. It includes the names of the patients of that health service who are under treatment. The situation of each patient in the current month must be registered. In the first instance, this information can be obtained from the Tb treatment record and control Book (black book). The social health service will fill out the information about the situation of the patients and send it back for registration.

\section{RESULTS}

The records indicated that, in 1998, among the total of $287 \mathrm{~Tb}$ patient cases referred to the Epidemiological Control Center of Ribeirão Preto, 55 (19\%) patients received ST, while the rest of them were accompanied on a monthly basis on the occasion of their return for a doctor's appointment. The patients or a member of their family were responsible for taking the medication. In 1999, then, ST covered 30\% among a total of 259 observed cases, which included patients followed up at the AIDS clinic of the Hospital das Clínicas of the University of São Paulo at Ribeirão Preto Medical School (HCFMRP).

With respect to gender, it was observed that, for 1998 and $1999,64 \%$ and $71 \%$ of the group covered by ST were men (Table 1). 
Table 1 - Distribution of the Tb cases admitted to ST, notified by the Epidemiological Control Center of the Municipal Health Secretariat of Ribeirão Preto, according to gender, in 1998 and 1999

\begin{tabular}{cccc}
\hline $\begin{array}{c}\text { Year } \\
\text { Gender }\end{array}$ & 1998 & 1999 & Total \\
\hline Male & 35 & 55 & 90 \\
Female & 20 & 22 & 42 \\
\hline Total & 55 & 77 & 132 \\
\hline
\end{tabular}

Source: Municipal Health Secretariat of Ribeirão Preto - Epidemiological Control Center

Table 2 shows the distribution of Tb cases covered by ST, which were studied according to the end of the treatment in 1998 and 1999. It was observed that, in both years, most of the cases evolved towards cure. Abandonment and death caused by Tb were the next two motives for treatment results.

Table 2 - Distribution of the Tb cases admitted to ST, notified by the Epidemiological Control Center of the Municipal Health Secretariat of Ribeirão Preto, according to the end of the treatment, in 1998 and 1999

\begin{tabular}{lccc}
\hline \multicolumn{1}{c}{$\begin{array}{c}\text { Year } \\
\text { End of treatment }\end{array}$} & 1998 & 1999 & Total \\
\hline Cure & 49 & 59 & 108 \\
Abandonment & 4 & 8 & 12 \\
Death not of Tb & 2 & 8 & 10 \\
Diagnosis Change & 0 & 1 & 1 \\
Transference & 0 & 1 & 1 \\
Death by Tb & 0 & 0 & 0 \\
In process & 0 & 0 & 0 \\
\hline Total & 55 & 77 & 132 \\
\hline
\end{tabular}

Source: Municipal Health Secretariat of Ribeirão Preto - Epidemiological Control Center

Where cure was concerned, $89 \%$ of the total number of cases evolved towards cure in 1998, while $77 \%$ of the cases were cured in 1999. Although ST covered a higher number of patients in 1999, the reduction in the cure rate is justified by the inclusion of Aids patients from the HCFMRP clinic.

Nowadays, one of the main problems for Tb control in Brazil has been treatment abandoning, which reaches $14 \%$. This percentage amounts to $30 \%$ in Rio de Janeiro and $20 \%$ in São Paulo. This contributes to the rise in the amount of multiresistant Tb cases ${ }^{(6)}$. The corresponding data for 1998 reveal a $7 \%$ abandonment rate for patients submitted to ST. This percentage increased by $3 \%$ in 1999 , which was most probably due to the short implementation time of ST.

With respect to $\mathrm{Tb}$ deaths in this group, $4 \%$ was found for 1998 and $10 \%$ for 1999. HIV infection may have interfered in this result, due to the high mortality rate among HIV positive patients ${ }^{(7)}$. No other deaths of other causes were identified in the period.

Table 3 presents the distribution of Tb cases according to HIV positive condition or not for 1998 and 1999. For 1998, among the total of notified Tb cases submitted to ST (55 cases), 12 (22\%) were infected by HIV, 9 of which (75\%) evolved towards cure, while $2(17 \%)$ abandoned the treatment and $1(8 \%)$ patient died of other motives than Tb. In 1999, in this group (77 cases), $41.6 \%$ of the patients were HIV positive, $20(62 \%)$ patients evolved towards cure, $6(19 \%)$ abandoned the treatment and $6(19 \%)$ died of other motives than $\mathrm{Tb}$.

Table 3 - Distribution of the Tb cases admitted to ST, notified by the Epidemiological Control Center of the Municipal Health Secretariat of Ribeirão Preto, according to the HIV immunology result, in 1998 and 1999

\begin{tabular}{|c|c|c|c|}
\hline Year & 1998 & 1999 & Total \\
\hline Negative & 27 & 38 & 65 \\
\hline Positive & 12 & 32 & 44 \\
\hline Not realized & 16 & 7 & 23 \\
\hline Total & 55 & 77 & 132 \\
\hline
\end{tabular}

Source: Municipal Health Secretariat of Ribeirão Preto - Epidemiological Control Center

Although the anti-HIV exam is recommended for all Tb cases, $23(17 \%)$ Tb patients submitted to ST were not tested in the analyzed period.

The age and occupation variables were not investigated according to treatment type. Nevertheless, the authors believe that their description in the group of Tb patients for the analyzed period would add information about the service demand profile. In 1998 and 1999, $53 \%$ of the $\mathrm{Tb}$ cases were young adults (20 to 39 years), who represented the most productive sector of the population.

For the two years studied here, were after $3 \%$ of persons less than 5 years old and 47 cases (9\%) of patients older than 50 , which demonstrated that this disease may hit people of all ages and that specific protection measures like the BCG vaccine must be implemented in accordance with TCP norms.

Ocupation data revealed that $\mathrm{Tb}$ cases were related to lessqualified activities that require a lower educational level, such as civil construction (16\%), domestic activities (9\%); unemployed persons (7\%), agricultural workers (3\%), among others.

\section{DISCUSSION}

Tb is linked up with the socioeconomic situation of a region or country. Hence, apart from a bacillus, multiple factors lie at the basis of the disease. Unemployment and the decrease in non-specialized labor wages created concentrations of poor people in urban areas. High unemployment and underemployment rates and decreased wages are found in the Brazilian society, together with bad transport and habitation conditions, underfeeding and famine; these are favorable conditions for $\mathrm{Tb}$, which make the disease even more serious ${ }^{(8)}$. 
The nursing team's participation in ST is essential, due to the fact that $\mathrm{Tb}$ demands prolonged treatment and given the hepatotoxicity of tuberculostatics. The patient may start to display irregular medication intake after symptom improvement, resulting in delayed patient recovery and even treatment failure.

When ST was implemented, home visits were adopted as a strategy for supervising medication intake, allowing the nursing team to establish links with the patients, making them co-responsible for their recovery. Nursing functions include offering guidelines on the diagnosis, medication treatment, hygiene and diet measures and contact control, among others.

The Health Units must consider the occupational variable in planning and developing their activities, like the educational actions directed at this public for example, since their language must be adequate for the cognitive capability of the users. The health professionals should value the public's knowledge and beliefs, seeking to adapt them to current concepts, besides providing new information and clearing up the doubts of the $\mathrm{Tb}$ patients and communicators in a receptive, productive and dynamic way.

The obtained results disclosed a tendency towards the gradual amplification of ST since, despite the decreased cure and increased abandonment rates in 1999, which were attributed by the AIDS patients, it must be considered that ST implementation, which was associated with the reorganization of the TCP activities, caused important changes in the epidemiological indices of $\mathrm{Tb}$. Nevertheless, efforts have to be continued with a view to increasing cure rates.

\section{REFERENCES}

1. Watanabe A, Ruffino ANeto . Aspectos Epidemiológicos da co-infecção Tb/HIV - Ribeirão Preto- SP. Medicina 1995 out/dez; 28(4):856-65.

2. Silva, CL. Implementação de estratégias na área de pesquisa e controle da Tuberculose no Brasil. Anais do $1^{0}$ Workshop Rede Brasileira de Pesquisa em Tuberculose; 15-19 setembro 2002; Rio de Janeiro, RJ. Rio de Janeiro: REDE-TB; 2002.

3. Ministério da Saúde. (BR). Plano Nacional de Controle da Tuberculose. Brasília (DF): Ministério da Saúde; 1999.

4. Muniz JN, Villa TCS, Pedersolli CE. O tratamento supervisionado no controle da Tuberculose em Ribeirão Preto: novo modo de agir em saúde. Bol Pneumol Sanitária 1999 jan/jun; 7(1):33-42.

5. Morrone N, Solha MSS, Cruvinel MC, Morrone N Júnior, Freire JAS, Barbosa ZLM. Tb: tratamento supervisionado "vs" tratamento auto-administrado. J Pneumol 1999 jul/ago; 25(4):198-206.

6 . Souza FB, Tocantins FR. Contactantes de doentes com TBMR possibilidade de intensificar a ação da Enfermagem. Bol Pneumol Sanitária 1999 jan/jun; 7(1).

7. Gazetta CE. Aspectos epidemiológicos da tuberculose em São José do Rio Preto-SP de 1993 a 1998, a partir das notificações da doença em um hospital escola. [Dissertação]. Ribeirão Preto (SP): Escola de Enfermagem de Ribeirão Preto/USP; 1999.

8. Ministério da Saúde (BR). Fundação Nacional da Saúde. Centro Nacional de Pneumologia Sanitária. Centro Nacional de Epidemiologia. Centro de Referência Hélio Fraga. Plano nacional de controle da tuberculose. Brasília (DF): Ministério da Saúde; 1999. 